\title{
Poly-arginine R18 and R18D (D-enantiomer) peptides reduce infarct volume and improves behavioural outcomes following perinatal hypoxic-ischaemic encephalopathy in the P7 rat
}

\author{
Adam B. Edwards ${ }^{1,2,3}$, Jane L. Cross ${ }^{1,3,4}$, Ryan S. Anderton ${ }^{1,2,4}$, Neville W. Knuckey ${ }^{1,3,4}$ and Bruno P. Meloni ${ }^{1,3,4^{*}}$
}

\begin{abstract}
We examined the neuroprotective efficacy of the poly-arginine peptide R18 and its D-enantiomer R18D in a perinatal hypoxic-ischaemic (HI) model in P7 Sprague-Dawley rats. R18 and R18D peptides were administered intraperitoneally at doses of $30,100,300$ or $1000 \mathrm{nmol} / \mathrm{kg}$ immediately after $\mathrm{HI}\left(8 \% \mathrm{O}_{2} / 92 \% \mathrm{~N}_{2}\right.$ for $\left.2.5 \mathrm{~h}\right)$. The previously characterised neuroprotective JNKI-1-TATD peptide at a dose of $1000 \mathrm{nmol} / \mathrm{kg}$ was used as a control. Infarct volume and behavioural outcomes were measured $48 \mathrm{~h}$ after $\mathrm{HI}$. For the R18 and R18D doses examined, total infarct volume was reduced by $25.93 \%$ to $43.80 \%$ ( $P=0.038$ to $<0.001$ ). By comparison, the JNKI-1-TATD reduced lesion volume by 25.27\% ( $P=0.073)$. Moreover, R18 and R18D treatment resulted in significant improvements in behavioural outcomes, while with JNKI-1-TATD there was a trend towards improvement. As an insight into the likely mechanism underlying the effects of R18, R18D and JNKI-1-TATD, the peptides were added to cortical neuronal cultures exposed to glutamic acid excitotoxicity, resulting in up to 89,100 and $71 \%$ neuroprotection, respectively, and a dose dependent inhibition of neuronal calcium influx. The study further confirms the neuroprotective properties of polyarginine peptides, and suggests a potential therapeutic role for R18 and R18D in the treatment of HIE.
\end{abstract}

Keywords: Hypoxic-ischaemic encephalopathy, Hypoxia-ischaemia, Neuroprotection, Poly-arginine peptides, R18, Cationic arginine-rich peptides (CARPs)

\section{Introduction}

In the human neonate, hypoxic-ischaemic encephalopathy (HIE) remains the leading cause of neonatal mortality and morbidity, with a reported incidence of $1-3$ per 1000 live term births [1], [2]. Neurological sequelae associated with HIE include cerebral palsy, epilepsy, mental retardation and learning disabilities [3]. Clinically, treatment to reduce brain injury for HIE is extremely limited, consisting of moderate hypothermia $\left(32-34{ }^{\circ} \mathrm{C}\right)$, maintained for up to $72 \mathrm{~h}$. While hypothermia appears to be

\footnotetext{
* Correspondence: bruno.meloni@perron.uwa.edu.au

${ }^{1}$ Perron Institute for Neurological and Translational Sciences, QEll Medical Centre, RR Block, Ground Floor, 8 Verdun St, Nedlands, WA 6009, Australia ${ }^{3}$ Department of Neurosurgery, Sir Charles Gardiner Hospital, QEll Medical Centre, Western Nedlands 6009, Australia

Full list of author information is available at the end of the article
}

well tolerated, its safety has only been assessed in fullterm infants (37-40 weeks gestation), hence no treatments are available for preterm neonates with HIE born before 37 weeks gestation. In addition, while hypothermia has been shown to improve outcomes in clinical trials, $31-55 \%$ of infants do not benefit from the therapy and suffer severe neurological sequelae [4]. Furthermore, hypothermia can only be used in hospital settings that have the necessary equipment and trained staff to induce and monitor hypothermia following HIE, and thus is not available in non-tertiary hospitals or hospitals located in remote locations and in many developing countries.

Due to the need for additional neuroprotective strategies for HIE, research has focused on the development of a pharmacological neuroprotective agent that can be 
administered alone and/or in combination with current hypothermia treatment to improve neonatal outcomes in HIE. An added advantage of a pharmacological neuroprotective agent is the possibility it can be used in remote locations, is effective in preterm infants, and/or can improve neuroprotective outcomes for hypothermia. We and others have recently demonstrated that cationic arginine-rich and poly-arginine peptides (hereafter referred to as CARPs) have potent neuroprotective properties in in vitro excitotoxicity neuronal injury models [513], as well as in animal stroke models [10, 11, 14-16]. In particular, we have demonstrated that the polyarginine peptide, $\mathrm{R} 18$, is highly neuroprotective in permanent and transient middle cerebral artery occlusion (MCAO) stroke models [11, 14-16].

While the exact mechanisms of the neuroprotective effects are still being explored, we and others have demonstrated that CARPs, including "putative" neuroprotective peptides fused to cationic arginine-rich cell penetrating peptides (i.e. TAT or R9; e.g. JNKI-1-TATD, TATNR2B9c/NA-1, TAT-CBD3/R9-CBD3-A6K and TAT3.2-III-IV) have the ability to mitigate excitotoxic or potassium evoked neuronal intracellular calcium influx [7, $8,17-19]$, and in doing so, likely suppress damaging down-stream signaling and cell death pathways. Beyond this, we have demonstrated that the poly-arginine R12 and TAT-NR2B9c/NA-1 peptides reduce neuronal cell surface expression of the glutamate receptor subunit NR2B [20]. The ability of CARPs to reduce neuronal cell surface levels of NR2B (due to internalization during endocytic uptake) is at least one mechanism whereby the peptides reduce the damaging effects of glutamateinduced calcium influx and excitotoxicity. Additionally, other "putative" neuroprotective peptides bound to TAT or R9 have been shown to reduce neuronal surface expression or activity of NMDA receptors [5, 21-23], as well as voltage gated calcium channels CaV2.2 [21, 24, 25] and CaV3.3 [18], and the sodium calcium exchanger 3 (NCX3) [21]. Given their effects on different receptors, presently, it cannot be ruled out that CARPs, due to their cationic charge, are also antagonizing ion channel receptor function directly and/or affecting calcium ion influx via an electrostatic mechanism $[7,9]$.

In addition to CARPs reducing the effects of excitotoxicity, based on other properties of this class of peptide, they may exert more pleiotropic neuroprotective effects by targeting mitochondria and maintaining mitochondrial integrity $[6,26-32]$, thereby reducing reactive oxygen species (ROS) production and release of pro-cell death proteins such as cytochrome-c. Furthermore, CARPs have the capacity to inhibit proteolytic enzymes including the proteasome $[33,34]$, as well as proprotein convertases [35-37] that activate matrix metalloproteinases (MMPs) [38]. Inhibition of the proteasome is known to be beneficial following cerebral ischaemia [39, 40], a mechanism that could be mediated by increased activity of hypoxia-inducible factor 1- $\alpha$ (HIF1 $\alpha)$ and decreased activity of nuclear factor $\kappa$-light-chain-enhancer of B cells (NFkB). Similarly, due to the damaging effects of MMPs on the neurovascular unit and blood brain barrier, any down-regulation of their proteolytic activity is likely to be beneficial following brain HI. In addition, there is also evidence that CARPs can activate prosurvival signaling pathways $[17,41]$ and modulate immune responses [42-44], as well as act as anti-oxidant molecules in their own right due to their guanidino group containing arginine residues [32, 45-49].

Since HIE and stroke are thought to share many pathophysiological processes (e.g. excitotoxicity and oxidative stress) it is likely that R18 will also be effective in reducing $\mathrm{HI}$ brain injury. To this end, several CARPs, including "putative" neuroprotective peptides fused to TAT such as JNKI-1-TATD [50], P5-TAT [51], TATNDB [52], TAT-mGluR1 [53], TAT-NR2B9c/NA-1 [53], IDR-1018 [54], and COG133 [55], have demonstrated efficacy in perinatal HI models. Importantly, CARPs like the TAT peptide also have cell penetrating properties and can cross the blood brain barrier and enter the brain [56-58].

Therefore, given the demonstrated efficacy of the R18 poly-arginine peptide in a number of experimental stroke studies $[11,14-16]$, the present study examined the neuroprotective efficacy and dose responsiveness of $\mathrm{R} 18$, as well as its D-amino acid enantiomer (R18D) in a perinatal HI model in the P7 Sprague-Dawley rat, and their effects on neuronal calcium influx in an in vitro glutamic acid excitotoxicity model. In addition, as a control, the study also examined the effects of the cationic arginine-rich JNKI-1-TATD peptide, which has previously been shown to be neuroprotective in various rodent brain injury models, including perinatal HI $[50,59]$.

\section{Methods}

\section{Animal ethics and study design}

All experimental procedures in this study adhered to the guidelines approved and specified by the Animal Ethics Committee of the University of Western Australia (RA/ 3/100/1329), in accordance with the Policies and Guidelines of the National Health and Medical Research Council, Australia. Treatments were randomised and all procedures (e.g. peptide administration, behavioural testing and infarct volume analysis) were performed while being blinded to treatments.

\section{Peptides used in the study}

Peptides used in the study are shown in Table 1. R18, R18D and JNKI-1-TATD used were synthesised by Mimotopes (Melbourne, Australia). Peptides were purified 
Table 1 Peptides used in study

\begin{tabular}{lllll}
\hline Peptide & Sequence $^{a}$ & Arginine/AA residues & $\begin{array}{l}\text { \% Arginine } \\
\text { residues }\end{array}$ & Net charge \\
\hline R18 & H-RRRRRRRRRRRRRRRRRR-OH & $18 / 18$ & 100 & 1800 \\
R18D & H-rrrrrrrrrrrrrrrr-OH & $18 / 18$ & 100 & +18 \\
JNKD & H-tdqsrpvqpflnlttprkprpp-rrrqrrkkrg-NH 2 & $9 / 32$ & 28 & $+12+$ \\
\hline
\end{tabular}

${ }^{a}$ At the $\mathrm{N}$-terminus, $\mathrm{H}$ indicates free amine. At the $\mathrm{C}$-terminus, $\mathrm{OH}$ indicates free acid, and $\mathrm{NH}_{2}$ indicates amide. $\mathrm{AA}=$ amino acids. Lowercase single letter code indicates D-isoform of the amino acid. JNKD = JNKI-1-TATD

using high performance liquid chromatography to at least 98\% purity, and were subject to peptide hydrolysis and amino acid liquid chromatography analysis to obtain a precise measure of peptide content.

For the in vitro and animal studies, peptides were prepared as a $500 \mu \mathrm{M}$ stock solution in water for irrigation (Baxter, Australia), and in $0.9 \%$ sodium chloride for injection (Pfizer, Australia), respectively. Reconstituted peptides were stored at $-20{ }^{\circ} \mathrm{C}$ until use.

\section{Surgical procedure for modified Rice-Vannucci model}

We used a modified Rice-Vannucci HI model. This involved occluding the right common, as well as the right external carotid artery, a procedure that we have previously demonstrated to lead to the generation of a highly reliable infarct [60]. Briefly, unsexed, Sprague-Dawley P7 rat pups (Animal Resource Centre, Murdoch, Australia; P0 = day of birth) with a body weight of 13-16 g were used. Litters were culled to a maximum of 12 pups per litter to facilitate uniform growth without littermate competition. Rat pups were anaesthetised using isoflurane (5\% induction, $1-2 \%$ maintenance) in $100 \%$ oxygen, while on a heating pad $\left(37^{\circ} \mathrm{C}\right)$. Through a $1 \mathrm{~cm}$ mid-line ventral incision, the right common, internal and external carotid arteries were exposed and isolated from the vagus nerve, venous circulation and carotid body. The right common carotid and external carotid arteries were permanently ligated using 6-0 silk sutures. The wound was closed using Vetbond (3M, Maplewood, USA) and the animals were recovered on $100 \%$ oxygen for $5 \mathrm{~min}$ on a heating pad. The duration of anaesthesia from induction to beginning of recovery was between 5 and $8 \mathrm{~min}$. Animals were provided with analgaesia (pethidine, $5 \mathrm{mg} / \mathrm{kg}$; intraperitoneally) immediately before cessation of anaesthesia. Sham-operated animals underwent the same operative procedure, except the exposed carotid arteries were not ligated.

Rat pups were returned to their dam for $1 \mathrm{~h}$ before the commencement of hypoxia which consisted of placing 4 to 6 pups in an airtight container (approximate volume: $4 \mathrm{~L}$ ) and exposing them to humidified and warmed hypoxic gas $\left(8 \% \mathrm{O}_{2} / 92 \% \mathrm{~N}_{2} ; 3 \mathrm{~L} / \mathrm{min}\right)$ for $2.5 \mathrm{~h}$. The container was placed inside an incubator with an ambient air temperature of $35{ }^{\circ} \mathrm{C}$, ensuring a body temperature of $36-37{ }^{\circ} \mathrm{C}$, which was periodically monitored using an infrared thermometer. Following hypoxia, animals were placed on a heating pad for $5 \mathrm{~min}$ in a normoxic environment before being placed back with the dam. Shamoperated animals remained with the dam at all times.

\section{Peptide administration}

Immediately after hypoxia, treatments were administered intraperitoneally ( $50 \mu \mathrm{l}$ bolus) and consisted of either the vehicle (saline; $0.9 \%$ sodium chloride), or R18 or R18D at four different doses $(30,100,300$ or $1000 \mathrm{nmol} / \mathrm{kg}$ ) or JNKI-1-TATD at a single dose $(1000 \mathrm{nmol} / \mathrm{kg})$.

\section{Animals used and sample size}

One hundred and thirty-three Sprague-Dawley P7 pups housed under controlled conditions on a 12-h light-dark cycle underwent surgery for $\mathrm{HI}$ or the sham procedure (i.e. anesthesia, neck incision, wound closure and analgesia). Twenty-seven animals were excluded from the study; a list of animal exclusions is provided in Table 2. The saline treatment group consisted of 19 animals and the sham group 6 animals. All other treatment groups consisted of between 7 and 11 animals (see Fig. 1a and Table 3). Additional vehicle treated animals were included in the study to ensure that each batch of animals subjected to HI contained a vehicle control and to increase the statistical power of the study.

\section{Infarct volume assessment}

Forty-eight hours after HI, animals were euthanised by pentobarbital overdose (50 $\mathrm{mg} / \mathrm{kg}$; intraperitoneally). Infarct volume was determined by preparing $2 \mathrm{~mm}$ thick coronal brain slices, and incubating in 3\% 2,3,5-triphenyltetrazolium chloride (TTC; Sigma Aldrich, St. Louis, USA) at $37{ }^{\circ} \mathrm{C}$ for $20 \mathrm{~min}$, followed by fixation in $4 \%$ formalin at room temperature overnight. Digital images of coronal slices were acquired using a colour scanner and analysed, using ImageJ software (3rd edition, NIH, Bethesda, USA). Total infarct volume was determined by measuring areas of infarcted tissue on both sides of the $2 \mathrm{~mm}$ slices. Infarct volume measurements were corrected for a degree of hemisphere volume changes [60]. Final infarct data is expressed as percentage infarct volume compared to whole brain (minus cerebellum). For analysis of infarct volumes in male and female animals, 
Table 2 Animals excluded in the study

\begin{tabular}{|c|c|c|c|c|}
\hline Exclusion rationale & Number of exclusions & Peptide & Dose & Total number of exclusions \\
\hline \multirow[t]{9}{*}{ No detectable infarct } & 3 & Saline & - & 15 \\
\hline & 1 & R18 & 300 & \\
\hline & 3 & R18 & 100 & \\
\hline & 2 & R18 & 300 & \\
\hline & 1 & R18 & 1000 & \\
\hline & 2 & R18D & 30 & \\
\hline & 1 & R18D & 300 & \\
\hline & 1 & R18D & 1000 & \\
\hline & 1 & JNKD & 1000 & \\
\hline Hyperthermia $^{a}$ & 1 & R18 & 1000 & 1 \\
\hline $\begin{array}{l}\text { Failure to complete behavioural } \\
\text { assessment }\end{array}$ & 3 & - & - & 3 \\
\hline Surgical haemorrhage ${ }^{b}$ & 5 & - & - & 5 \\
\hline Premature death ${ }^{c}$ & 3 & - & - & 3 \\
\hline
\end{tabular}

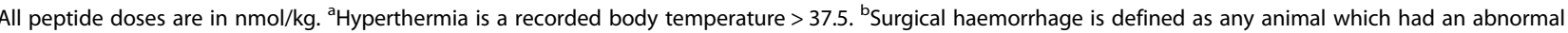
bleed (arterial rupture) during the surgical parameter. 'Premature deaths occurred during hypoxia. JNKD = JNKI-1-TATD

due to low numbers of each gender per group, data for the different doses of R18 and R18D were combined.

\section{Behavioural assessment}

To determine if the development of cerebral infarct was associated with reduced sensorimotor outcomes, three neurological tests (righting reflex, negative geotactic response and wire-hang) were performed at $48 \mathrm{~h}$ after $\mathrm{HI}$, as previously reported [60]. Briefly, for three consecutive days before surgery (P4 to P6 inclusive), pups were accustomed to behavioural assessments with a target inclusion range of $\leq 2 \mathrm{~s}$ for the righting reflex and $\leq 30 \mathrm{~s}$ for the negative geotactic response. Any animal that did not record responses within these parameters at P7 (day of surgery) were excluded from the experiment. All of these reflexes are highly reproducible throughout the murine pre-weaning period $(<$ P30) and are strain- and genderindependent [61]. Each animal was given three attempts to complete each sensorimotor task, with 5 min between each attempt. Testing of all reflexes was performed on a board covered with a tightly-stretched close knit-fabric, to ensure adequate friction.

The righting reflex involved placing pups in a supine position, and measuring the time required to rotate to the prone position. The negative geotactic response involved placing pups facing down-slope, on a $45^{\circ}$ angled surface, and measuring the time required for the animal to turn $150^{\circ}$ upslope. Wire-hang test was performed by suspending pups by their forelimbs on a $2 \mathrm{~mm}$ diameter steel wire suspended $20 \mathrm{~cm}$ above a foam surface, and recording the time taken for the animal to fall to the foam surface.

\section{Cortical neuronal cultures}

Establishment of rat primary cortical neuronal cultures was performed as previously described $[8,10]$. Briefly, cortical tissue was obtained directly from E18-day old embryos. Dissociated neurons were seeded into 96-wellsized glass wells $(7 \mathrm{~mm}$ diameter, Grace, Melbourne, Australia), 96-well plastic plates (Nunc, Thermo Fisher Scientific, Melbourne, Australia) in Neurobasal/2\% B27 supplement (Life Technologies, Melbourne, Australia) and maintained in a $\mathrm{CO}_{2}$ incubator $\left(5 \% \mathrm{CO}_{2}, 95 \%\right.$ air balance, $98 \%$ humidity) at $37{ }^{\circ} \mathrm{C}$ until use on day in vitro 10 to 14 . Under these conditions, cultures routinely consist of $>97 \%$ neurons and $1-3 \%$ astrocytes.

\section{Glutamic acid excitotoxicity}

A dose response experiment was performed as previously described [8]. Briefly, peptides in a $50 \mu \mathrm{l}$ volume in Minimum Essential Medium (Life Technologies)/2\% B27 supplement (MEM/B27) were added to culture wells for $10 \mathrm{~min}$ at $37{ }^{\circ} \mathrm{C}$ in the $\mathrm{CO}_{2}$ incubator before the addition of $50 \mu \mathrm{l} \mathrm{MEM} / \mathrm{B} 27$ containing glutamic acid $\mathrm{L}^{-}$ glutamic acid; Sigma-Aldrich: $200 \mu \mathrm{M}$; final concentration $100 \mu \mathrm{M}$ ). Following a $5 \mathrm{~min}$ incubation at $37^{\circ} \mathrm{C}$ in the $\mathrm{CO}_{2}$ incubator (note: peptide concentration reduced by half during this step), media was replaced with $100 \mu \mathrm{L}$ MEM/B27 and cultures wells were incubated for a further $24 \mathrm{~h}$ at $37^{\circ} \mathrm{C}$ in the $\mathrm{CO}_{2}$ incubator. Untreated controls with or without glutamic acid treatment underwent the same incubation steps and media additions.

At different times after treatment (e.g. 0.5 to $4 \mathrm{~h}$ and 18-24 h), cultures were examined by light microscopy for qualitative assessment of neuronal cell viability. Neuronal viability was quantitatively measured by MTS 


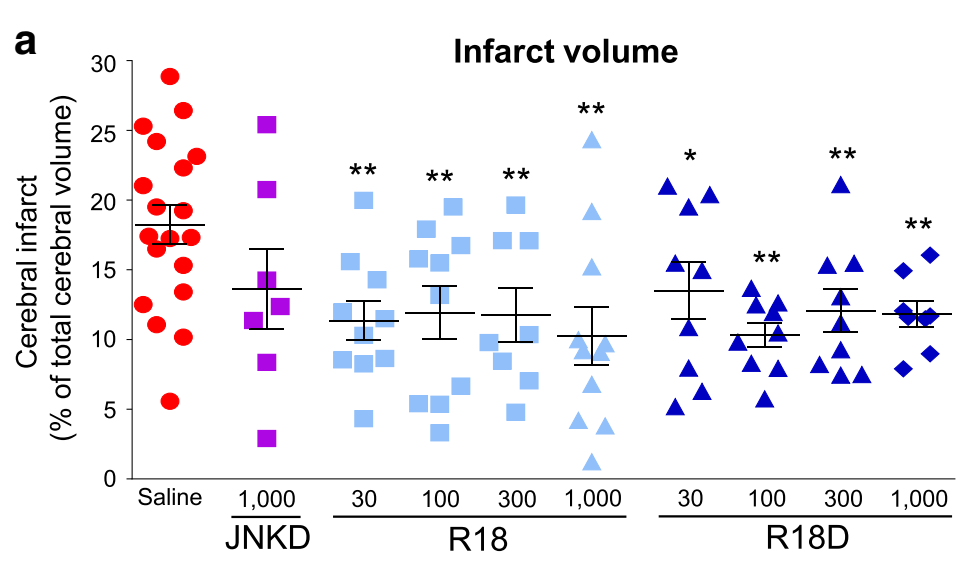

b

Infarct lesion

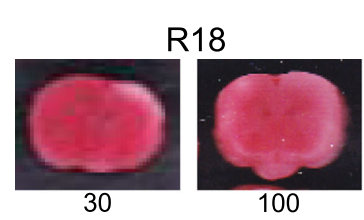

Saline
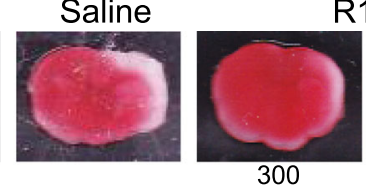

R18D
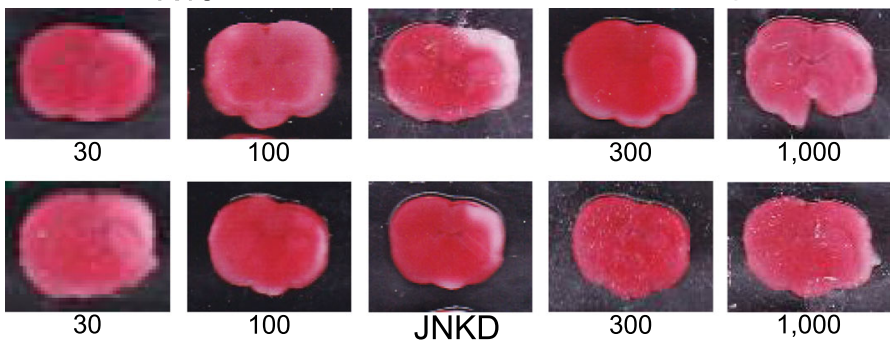

1,000

C

Coronal slices

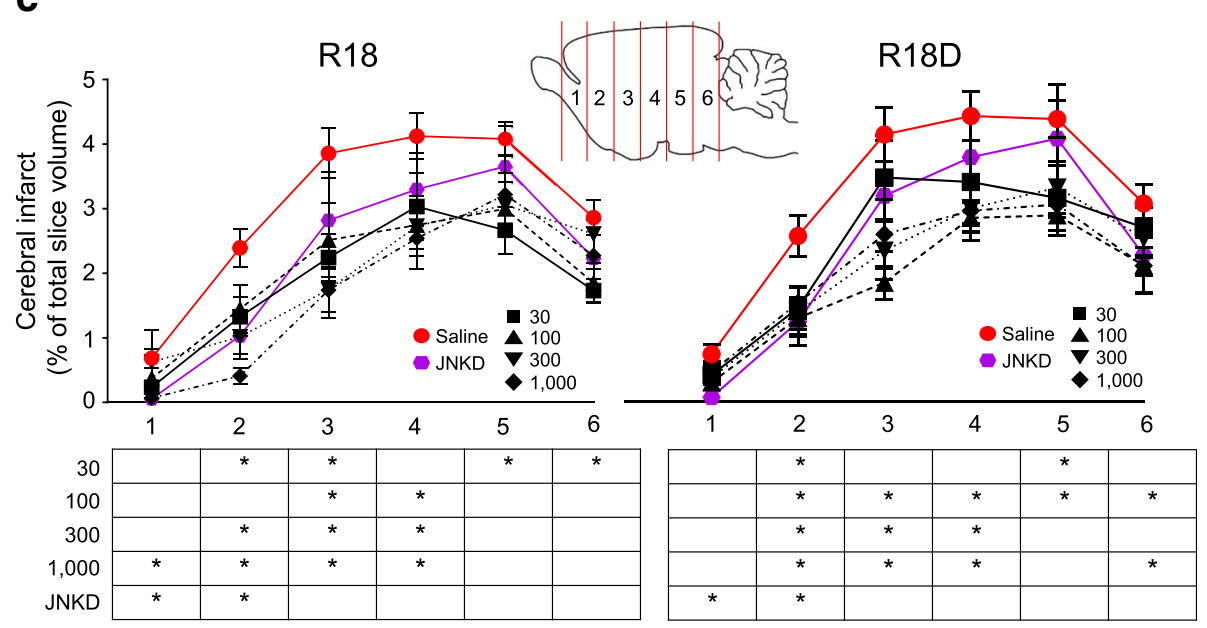

Fig. 1 Percentage infarct volume; percentage infarct volume, representative images of coronal brain slices and percentage infarct volume in brain slices for the different treatment groups as determined $48 \mathrm{~h}$ after HI. Treatments were administered intraperitoneally (saline or R18, R18D and JNKI-1-TATD; doses in $\mathrm{nmol} / \mathrm{kg}$ ) immediately after hypoxia. a Percentage of infarct volume when compared to total brain volume. b Representative TTC coronal brain slice 2, from saline and peptide treated animals. Minor adjustments to brightness and contrast has been made to improve digital images. $\mathbf{c}$ Infarct volume analysis in $2 \mathrm{~mm}$ coronal brain slices (slices numbered 1-6 from rostral to caudal) from saline and peptide treated animals. Statistical significance is expressed in the table. Values are mean $\pm \mathrm{SE} ;{ }^{*} P<0.05$, ${ }^{* *} P<0.01$ when compared to saline. JNKD $=$ JNKI-1-TATD

(3-(4,5,dimethyliazol-2-yl)-5-(3-carboxymethoxyphenyl)-2-(4-sulfophenyl)-2H-tetrazolium salt) assay (Promega, Sydney, Australia). The MTS absorbance data were converted to reflect proportional cell viability relative to both the untreated (no insult; $100 \%$ viability) and treated (glutamic acid; 5\% viability) controls. At least four wells were used in assays, repeated a minimum of three to four times independently.

\section{Intracellular calcium kinetics}

Intracellular calcium influx was monitored as previously described [8]. Briefly, primary cortical neuronal cultures 
Table 3 Cerebral infarct. Percentage of total cerebral volume

\begin{tabular}{lllllll}
\hline Treatment & Dose & $N$ & Mean of total infarct volume (\%) & $\begin{array}{l}\text { SE } \\
(\%)\end{array}$ & Reduction in total infarct volume (\%) & $P$ \\
\hline Saline & - & 19 & 18.24 & 1.393 & - & - \\
JNKD & 1000 & 7 & 13.63 & 2.843 & 25.27 & 0.073 \\
R18 & 30 & 10 & 11.34 & 1.401 & 37.82 & $\mathbf{0 . 0 0 2}$ \\
& 100 & 10 & 11.93 & 1.924 & 34.59 & $\mathbf{0 . 0 0 4}$ \\
& 300 & 8 & 11.78 & 1.921 & 35.42 & $\mathbf{0 . 0 0 7}$ \\
R18D & 1000 & 11 & 10.25 & 2.082 & 43.80 & $\mathbf{0 . 0 0 1}$ \\
& 30 & 9 & 13.51 & 2.058 & 25.93 & $\mathbf{0 . 0 3 8}$ \\
& 100 & 9 & 10.33 & 0.874 & 43.36 & $\mathbf{0 . 0 0 1}$ \\
& 300 & 9 & 12.07 & 1.540 & 33.82 & $\mathbf{0 . 0 0 7}$ \\
& 1000 & 8 & 11.83 & 0.957 & 35.14 & $\mathbf{0 . 0 0 7}$ \\
\hline
\end{tabular}

$N$ number of animals, SE standard error of mean, $P$ calculated compared to saline vehicle control. All doses are in $\mathrm{nmol} / \mathrm{kg}$. Mean and SE expressed as percentage of total cerebral volume. JNKD $=$ JNKI-1-TATD. Percentage reduction is mean percentage reduction compared to saline. All values $P<0.05$ are in bold

were loaded with the fluorescent calcium ion indicator Fura-2 AM (5 $\mu \mathrm{M}$; Sigma Aldrich) in $50 \mu \mathrm{L}$ MEM/B27, $0.1 \%$ pluronic F-127 (Sigma Aldrich), for $20 \mathrm{~min}$ at $37^{\circ}$ $\mathrm{C}$ in the $\mathrm{CO}_{2}$ incubator. Fura-2 AM solution was removed from wells, replaced with $50 \mu \mathrm{L}$ MEM/B27 containing peptides (R18 and R18D;0.2, 2 and $5 \mu \mathrm{M}$ ) or NMDA and AMPA receptor blockers (MK801/CNQX; $5 \mu \mathrm{M} / 5 \mu \mathrm{M}$; Tocris Bioscience, Bristol, United Kingdom) and incubated for $10 \mathrm{~min}$ at $37^{\circ} \mathrm{C}$ in the $\mathrm{CO}_{2}$ incubator. Control cultures received $50 \mu \mathrm{L}$ of MEM/B27 only. After the $10 \mathrm{~min}$ incubation period, media in wells was replaced with $50 \mu \mathrm{L}$ of balanced salt solution (BSS: mM: $116 \mathrm{NaCl}, 5.4 \mathrm{KCl}, 1.8 \mathrm{CaCl}_{2}, 0.8 \mathrm{MgSO}_{4}, 1 \mathrm{NaH}_{2} \mathrm{PO}_{4}$; $\mathrm{pH}$ 7.2) and wells transferred to a spectrophotometer (BMG Labtec, CLARIOstar, Mornington, Australia) while maintaining temperature at $37{ }^{\circ} \mathrm{C}$. Fifty microliters of BSS containing glutamic acid $(200 \mu \mathrm{M} ; 100 \mu \mathrm{M}$ final concentration) was added to wells, and every $5 \mathrm{~s}$, starting $30 \mathrm{~s}$ before and for $90 \mathrm{~s}$ after glutamic acid addition, spectrophotometer measurements (excitation: $355 \mathrm{~nm} /$ emission $495 \mathrm{~nm}$ ) were recorded. Experiments were performed in triplicate. Area under the curve (AUC) for calcium kinetics data was calculated by trapezoidal approximation of the AUC using fluorescent kinetic data obtained after the addition of glutamic acid to wells.

\section{Statistical analysis}

The number of animals used in each experiment was justified by statistical power calculation based on a previous study [60]. Group sizes have been calculated based on a predicted treatment effect of $40 \%$, at a power level of $80-90 \%$ and an alpha level of 0.05 . Mean percentage infarct volume, behavioural measurements weight gain and neuronal viability data were analysed by analysis of variance (ANOVA), followed by post-hoc Fisher's PLSD test, with $P<0.05$ values considered statistically significant. All descriptive statistics are presented in Table 3 and Additional file 1: Table S1, Additional file 2: Table S2 and Additional file 3: Table S3.

\section{Results}

Infarct volume measurements

Data on infarct volume and representative TTC stained coronal brain slices are presented in Fig. 1a and b. When compared to the saline vehicle control (hereafter referred to as saline), both R18 and R18D significantly reduced infarct volume at all doses examined (30, 100, 300 and $1000 \mathrm{nmol} / \mathrm{kg})$ by between 25.27 and $43.80 \%(P=$ 0.045 and $<0.001$, respectively; refer to Table 3 for descriptive statistics). By comparison, the JNKI-1-TATD peptide $(1000 \mathrm{nmol} / \mathrm{kg})$ reduced infarct volume by 25.27\% $(P=0.073)$. No single R18, R18D or JNKI-1TATD dose was significantly more effective than any other dose. To assess infarct development within $2 \mathrm{~mm}$ coronal slices, rostral to caudal topographic analysis of infarcts revealed that R18, R18D and JNKI-1-TATD at all doses significantly reduced brain injury in one or more coronal slices 1 to 6 (Fig. 1c; refer to Additional file 1: Table S1 for descriptive statistics).

\section{Behavioural outcomes, weight gain and gender analysis}

Data on behavioural outcomes and weight gain is presented in Fig. $2 \mathrm{a}-\mathrm{h}$ and descriptive statistics presented in Additional file 2: Table S2. All data is transformed to demonstrate the percentage improvement from baseline for each treatment group, $48 \mathrm{~h}$ following HI. The sham procedure is taken as equivalent to $100 \%$ improvement and saline control to $0 \%$ improvement. The results of the righting reflex test demonstrated that R18 (30 and $1000 \mathrm{nmol} / \mathrm{kg}$ ) and R18D (300 and $1000 \mathrm{nmol} / \mathrm{kg}$ ) significantly improved the righting reflex time by between $53.95 \%$ and $79.88 \%(P=0.008$ and 0.007$)$, respectively, when compared to saline. In comparison, animals treated with JNKI-1-TATD (1000 nmol/kg) showed no 
R18

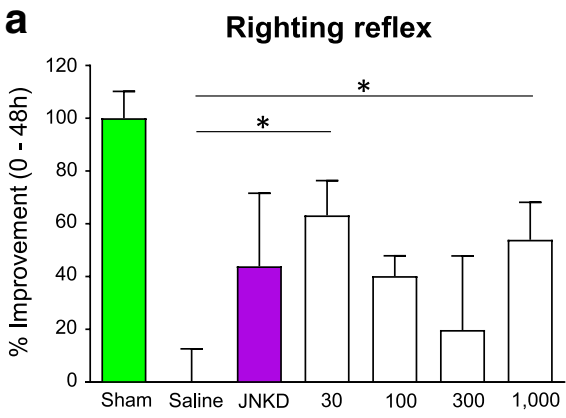

C

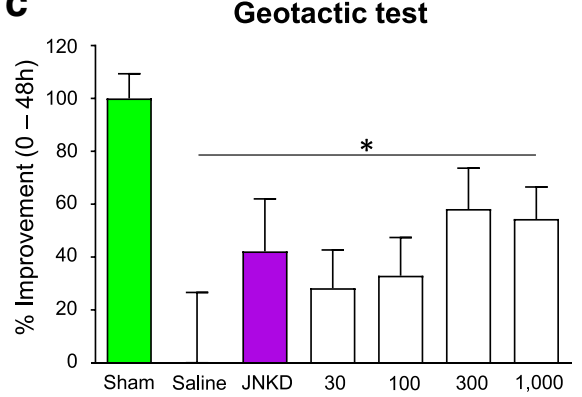

e

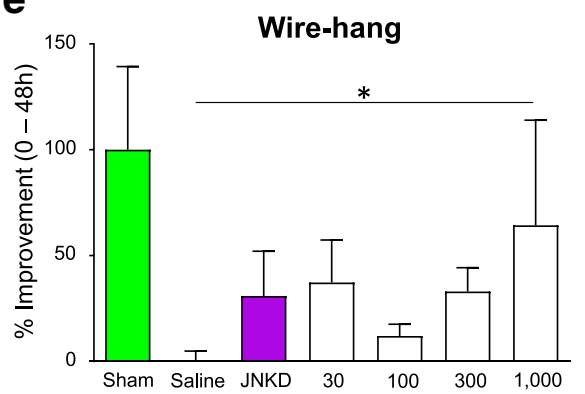

g

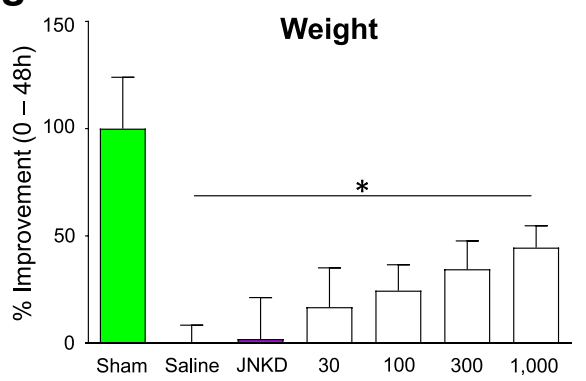

R18D

b

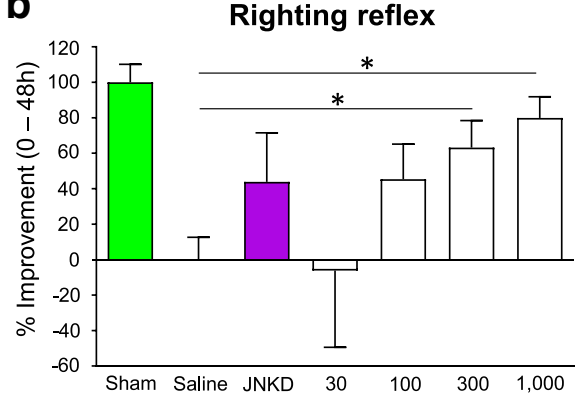

d

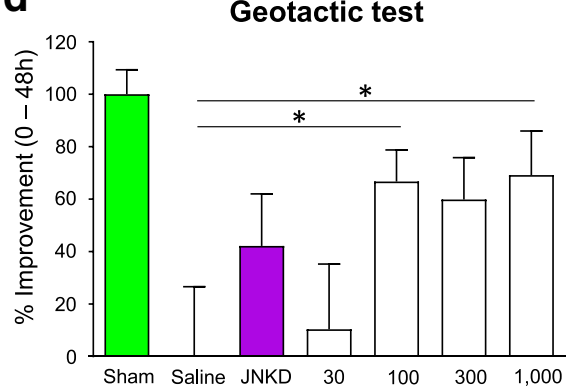

f

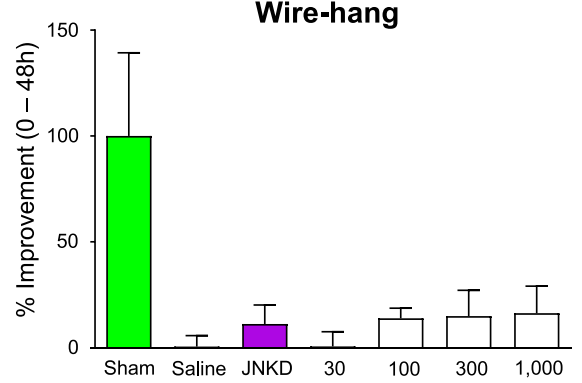

h

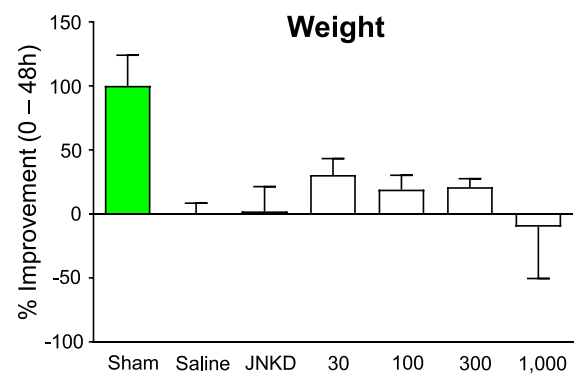

Fig. 2 Behavioural measurements using righting reflex, negative geotactic response, wire-hang test and weight gain $48 \mathrm{~h}$ after $\mathrm{HI}$. Treatments were administered intraperitoneally (saline, R18, R18D or JNKI-1-TATD; doses in nmol/kg). The sham procedure group was assessed $48 \mathrm{~h}$ following sham-surgery. a R18 righting reflex percentage improvement from 0 to $48 \mathrm{~h}$. b R18D righting reflex percentage improvement from 0 to 48 h. c R18 negative geotactic response percentage improvement from 0 to $48 \mathrm{~h}$. $\mathbf{d}$ R18D negative geotactic response percentage improvement from 0 to $48 \mathrm{~h}$. e R18 wire-hang percentage improvement from 0 to $48 \mathrm{~h}$. f R18D wire-hang percentage improvement from 0 to $48 \mathrm{~h}$. $\mathbf{g}$ R18 weight percentage improvement from 0 to 48 h. h R18D weight percentage improvement from 0 to $48 \mathrm{~h}$. Values are mean $\pm S E$. ${ }^{*} P<0.05$ when compared to saline. JNKD $=$ JNKI-1-TATD

statistically significant improvement, although there was a trend towards improvement $(43.87 \% ; P=0.063)$.

Analysis of the negative geotactic response test revealed that R18 (1000 nmol/kg) and R18D (100 and
$1000 \mathrm{nmol} / \mathrm{kg}$ ) significantly improved the time taken for animals to rotate $150^{\circ}$ up the $45^{\circ}$ slope when compared to saline by between $54.44 \%$ and $69.17 \%(P=0.049$ and $0.036)$, respectively. All other doses improved the 
negative geotactic response time by between $10.40 \%$ and $59.87 \%(P=0.738$ and 0.057$)$, respectively. In comparison, JNKI-1-TATD $(1000 \mathrm{nmol} / \mathrm{kg})$ resulted in no statistically significant improvement, although there was a trend towards improvement $(42.18 \% ; P=0.187)$.

For the wire-hang test, only R18 at a dose of $1000 \mathrm{nmol} / \mathrm{kg}$ resulted in a statistically significant improvement in the time animals held onto the wire, increasing hang-time by $64.29 \% \quad(P=0.033)$ when compared to saline. All other doses improved the wire hang time by between $0.59 \%$ and $37.26 \%(P=0.997$ and 0.227), respectively. By comparison, JNKI-1-TATD $(1000 \mathrm{nmol} / \mathrm{kg})$ resulted in no statistically significant improvement in the wire-hang time $(30.93 \% ; P=0.374)$.

Analysis of weight gain over $48 \mathrm{~h}$ revealed that R18 at a dose of $1000 \mathrm{nmol} / \mathrm{kg}$ was the only treatment to significantly improve weight gain $(44.59 \% ; P=0.009)$ when compared to saline (see Additional file 3: Table S3 for descriptive statistics), while all other doses of R18 and R18D demonstrated an increase in weight by between $16.83 \%$ and $34.49 \%(P=0.327$ and 0.065$)$, respectively. In comparison, JNKI-1-TATD $(1000 \mathrm{nmol} /$ $\mathrm{kg}$ ) treated animals demonstrated a gain in weight (1.94\%; $P=0.935)$. The only dose to demonstrate a loss of weight was R18D at $1000 \mathrm{nmol} / \mathrm{kg}(-10.01 \%$; $P=0.659$ ).

Analysis of R18 and R18D neuroprotective efficacy in male and female animals revealed a significant reduction in total infarct volume in both sexes when compared to male and female saline treated animals (Additional file 4: Figure S1; note: for analysis the different doses of R18 and R18D were combined). While intra-group comparisons demonstrated no significant differences in total infarct volumes between male and female animals treated with R18, R18D or saline; there was a trend towards reduced infarcts in female animals treated with R18 and R18D (Additional file 4: Figure S1).

\section{In vitro neuroprotective efficacy and calcium kinetics following glutamic acid excitotoxicity}

To provide an insight into the potential mechanism of action of R18 and R18D, in vitro neuroprotective efficacy and excitotoxic neuronal calcium influx kinetics were assessed. In line with previous findings from our laboratory R18 and JNKI-1-TATD [7, 10, 11], as well as R18D displayed dose-dependent neuroprotection following excitotoxicity (Fig. 3). For example, R18 and R18D increased neuronal survival from 5\% for the glutamic acid control to $89 \%$ and $83 \%$ and $96 \%$ and $100 \%$ at $1 \mu \mathrm{M}$ and $2 \mu \mathrm{M}$, respectively (Fig. 3). By comparison, JNKI-1-TATD increased neuronal survival to 23 and $71 \%$ at $1 \mu \mathrm{M}$ and $2 \mu \mathrm{M}$, respectively. As we have previously observed, higher peptide concentrations (i.e. $5 \mu \mathrm{M}$ ) can have a negative impact on neuronal survival [8], this was particularly evident for R18D, a fact which most likely reflects the higher stability of D-isoform peptides in the closed neuronal culture system [9].

Again, in line with our previous findings, R18 and JNKI-1-TATD [7, 10, 11], as well as R18D, reduced glutamic acid induced neuronal intracellular calcium influx in a dose dependent manner (Fig. 4). In addition, the calcium influx data for R18, R18D and JNKI-1-TATD correlated with their neuroprotective effectiveness following glutamic acid excitotoxicity, with JNKI-1-TATD displaying the least neuronal intracellular calcium influx inhibitory effects.

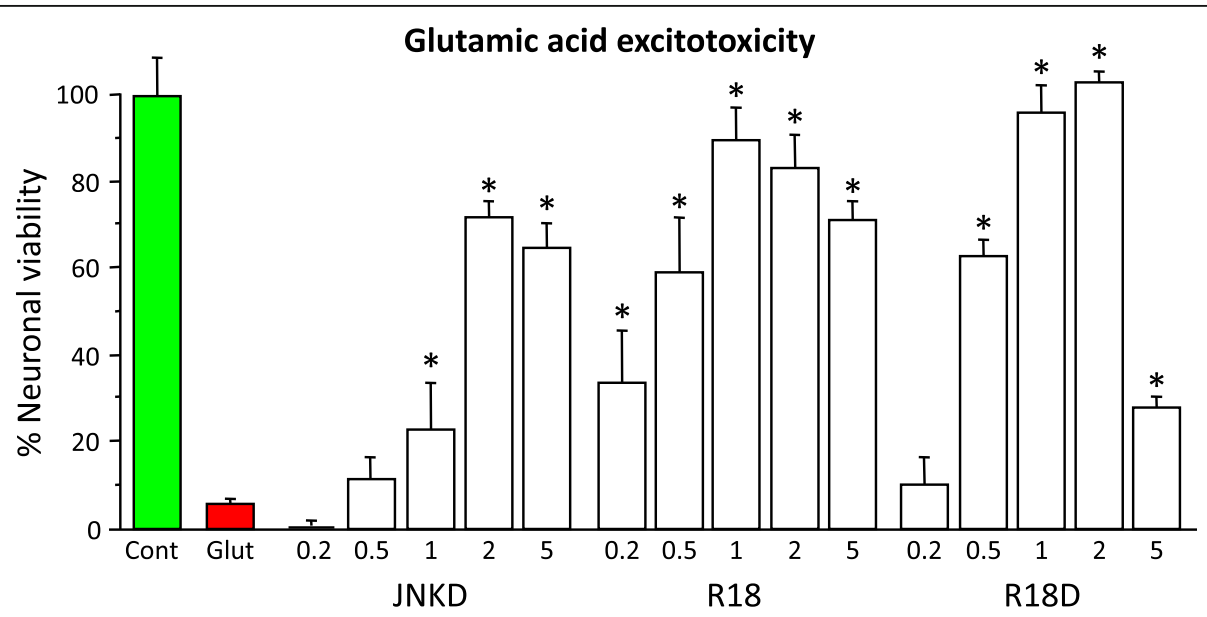

Fig. 3 Glutamic acid excitotoxicity model; R18, R18D and JNKI-1-TATD dose response study. Peptides present in neuronal cultures 10 min before and during 5 min glutamic acid exposure. Neuronal viability measured $24 \mathrm{~h}$ after glutamic acid exposure. Concentration of peptide in $\mu \mathrm{mol} / \mathrm{L}$. MTS data were expressed as percentage neuronal viability with no insult (100\% viability) and glutamic acid control (5\% viability). Values are mean \pm SE; $n=4$; ${ }^{*} P<0.05$ when compared to no glutamic acid control. Cont $=$ no treatment control. Glut $=$ glutamic acid control. JNKD $=$ JNKI-1-TATD 

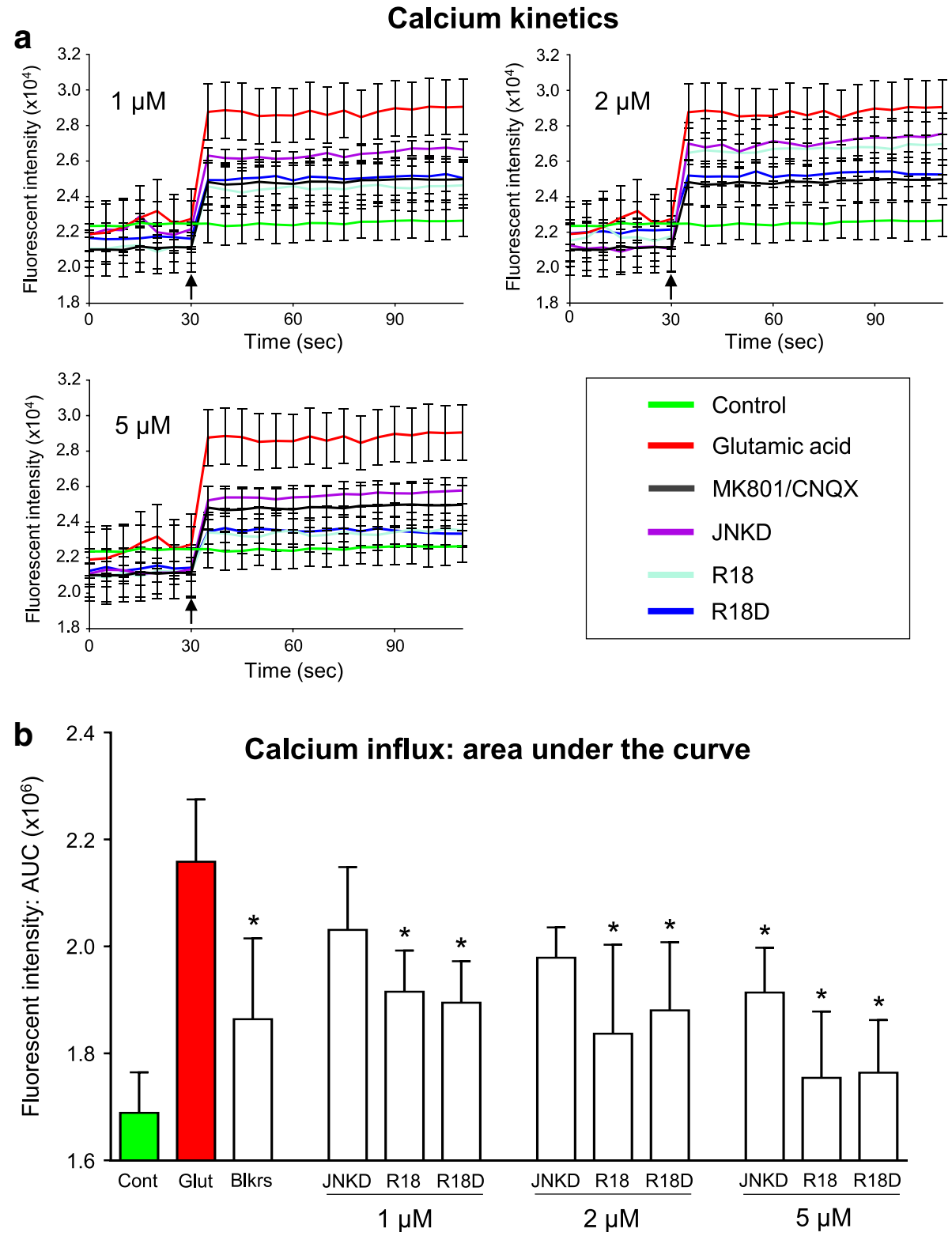

Fig. 4 Intracellular calcium assessment using Fura-2 AM after glutamic acid exposure in primary neuronal cultures. a Fluorescent Fura-2 AM tracers; fluorescent intensity (FI) of neuronal cultures $30 \mathrm{~s}$ before and after the addition (arrow) of glutamic acid (100 $\mu \mathrm{M}$ final concentration). Peptides (1, 2 and $5 \mu \mathrm{M}$ ) or glutamate receptor blockers (MK801/CNQX; $5 \mu \mathrm{M} / 5 \mu \mathrm{M}$ ) were added to neuronal cultures for $10 \mathrm{~min}$ and removed (time $=0$ ) before glutamic acid addition (time $=30 \mathrm{~s}$ ). Values are mean $\pm \mathrm{SE} ; n=3$. $\mathbf{b}$ Trapezoidal area under the curve (AUC) approximation of calcium kinetic tracers. AUC is determined at $35 \mathrm{~s}$ (point after glutamic acid addition. Values are mean $\pm \mathrm{SE} ; n=3 ;{ }^{*} P<0.05$ when compared to glutamic acid control. Cont $=$ no treatment control. Glut = glutamic acid control. Blkrs = glutamate receptor blockers (MK801/CNQX; $5 \mu \mathrm{M} / 5 \mu \mathrm{M})$. JNKD = JNKI-1-TATD

\section{Discussion}

The present study extends our previous findings examining the neuroprotective effectiveness of CARPs in in vitro and animal stroke injury models [7-11, 13-16]. In doing so, the data provides compelling evidence for the neuroprotective action of poly-arginine peptides R18 and R18D, as well as the JNKI-1-TATD peptide, which is also a CARP, in a modified Rice-Vannucci model of HIE. The modified Rice-Vannucci model used in this study leads to the generation of a more reproducible infarct, accompanied with a greater severity of brain injury [60]. The original and modified Rice-Vannucci models are likely to mimic the clinical development of a pattern of brain injury, whereby white matter and cerebral cortex, supplied by the middle cerebral and posterior cerebral arteries, are affected following prolonged birth asphyxia [62]. Importantly, the neuroprotective actions of R18 and R18D, as measured in terms of infarct volume, was 
associated with improved behavioural outcomes at a number of the peptide doses with respect to the righting reflex, negative geotactic response and wire-hang tests, while JNKI-1-TATD only demonstrated trends towards improvement in the righting reflex and negative geotactic response tests. In addition, unlike JNKI-1-TATD, some doses of R18 and R18D improved weight gain following HI. This is another indicator for improved behavioural outcomes as it is likely to reflect the animals' increased motor capacity to search and feed from the dam, as well as potential reduced weight loss due to increases in respiratory demand, metabolic rate and cachexia [63]. Furthermore, treatment with R18 and R18D was effective at reducing total infarct volume in both male and female animals following HI.

It is noteworthy that, the R18 and R18D were highly effective at reducing infarct volume at all doses examined without displaying a typical dose response effect. The efficacy of both R18 and R18D over a wide dose range $(30-1000 \mathrm{nmol} / \mathrm{kg})$ is highly significant, which ultimately could translate to the peptides being effective at low doses when used clinically following HIE. The effectiveness of JNKI-1-TATD (also referred to as XG-102) in a wide dose range with IP administration has also been demonstrated previously following transient MCAO in adult mice [64] and following permanent $\mathrm{MCAO}$ in P14 rats [65].

In the present study, R18 and R18D appeared more effective than JNKI-1-TATD across all the in vivo (infarct volume and behavioural outcomes) and in vitro (neuroprotection and neuronal intracellular calcium influx inhibition) outcomes examined. The lower efficacy of JNKI-1-TATD may reflect its lower arginine content ( $\mathrm{R}$ $=9)$ and cationic charge $(+12)$ compared to R18 and $\mathrm{R} 18 \mathrm{D}(\mathrm{R}=18$, charge $=+18)$. On this point, our previous studies have confirmed that CARP neuroprotective efficacy and neuronal excitotoxic influx inhibition increases with increasing peptide arginine content and peptide positive charge $[8,9]$. It is also noteworthy that in the present study, no obvious overall differences were uncovered between the R18 peptide and its R18D enantiomer.

As mentioned above, the only currently available treatment known to improve neurological outcomes following HIE is moderate hypothermia $\left(32-34{ }^{\circ} \mathrm{C}\right.$ for $72 \mathrm{~h}$ ). As such there is an urgent need for the development of an effective pharmacological neuroprotective agent that can be readily administered following HIE and that is compatible and synergistic with hypothermia. Therefore, it will be important in future studies to assess whether R18 or R18D treatment is compatible with hypothermia, and whether the combined therapies have an additional effect in reducing brain injury and improving behavioural outcomes. In addition, whilst a $48 \mathrm{~h}$ endpoint is commonly used in initial neuroprotective and pathophysiological investigations, it is important that the effectiveness of R18 and R18D at more extended timepoints should also be evaluated. We also recognise that the IP route for peptide administration may not be ideally suited to the clinical situation, and that an intravenous (IV) route would be preferable. Furthermore, due to the potential differences in blood pharmacokinetics following IP or IV administration of R18 and R18D, at present it is not known how the different delivery routes would impact on the neuroprotective efficacy of the peptides. To this end, further assessment of R18 and R18D when administered by the IV route could be more appropriately carried out in a large animal model of $\mathrm{HI}$ (i.e. piglet or lamb).

\section{Additional files}

\section{Additional file 1: Table S1. Cerebral infarct. Percentage of} topographical coronal slices. (DOCX $16 \mathrm{~kb}$ )

Additional file 2: Table S2. Behavioural assessment. (DOCX $17 \mathrm{~kb}$ ) Additional file 3: Table S3. Weight gain $48 \mathrm{~h}$ after hypoxia-ischaemia. (DOCX $16 \mathrm{~kb}$ )

Additional file 4: Figure S1. Gender comparison of infarct volume. (PPTX $59 \mathrm{~kb}$ )

\section{Abbreviations}

ANOVA: Analysis of variance; AUC: Area under the curve; CARPs: Cationic arginine rich peptides; HI: Hypoxia-ischaemia; HIE: Hypoxic ischaemic encephalopathy; HIF1a: Hypoxia-inducible factor 1-a; IP: Intraperitoneal; IV: Intravenous; MCAO: Middle cerebral artery occlusion; MEM: Minimum essential medium; MMPs: Matrix metalloproteinases; MTS: 3(4,5, dimethyliazol-2-yl)-5-(3-carboxymethoxy-phenyl)-2-(4-sulfophenyl)-2Htetrazolium salt; NCX3: Sodium calcium exchanger 3; NFkB: Nuclear factor kappa-light-chain enhancer of B cells; NMDA: N-methyl-D-aspartic acid; R12: Poly-arginine-12; R18: Poly-arginine-18; R18D: Poly-arginine-18 Denantiomer; R9: Poly-arginine-9; ROS: Reactive oxygen species; TTC: 2,3,5triphenyltetrazolium chloride

\section{Acknowledgments}

This study in part was supported by the Department of Neurosurgery, Sir Charles Gairdner Hospital. The authors acknowledge the feedback on the manuscript provided by Professors Frank Mastaglia and Norman Palmer.

\section{Funding}

This research was in part funded by the Sir Charles Gardiner Hospital, Department of Neurosurgery. This funding body had no part in the study, collection, analysis and interpretation of data.

Availability of data and materials

Please contact author for data requests.

\section{Authors' contributions}

$\mathrm{AE}$ and JC contributed to animal procedures, post-surgical monitoring, functional assessment, infarct volume or statistical analysis. AE and BM contributed to in vitro experiments. AE, RA, NK and BM contributed to experimental design and manuscript preparation. All authors read and approved the final manuscript.

Ethics approval and consent to participate Not applicable

Consent for publication

Not applicable 


\section{Competing interests}

B.P. Meloni and N.W. Knuckey are named inventors of several patent applications regarding the use of arginine-rich peptides as neuroprotective agents. The other authors declare no conflict of interest.

\section{Publisher's Note}

Springer Nature remains neutral with regard to jurisdictional claims in published maps and institutional affiliations.

\section{Author details}

'Perron Institute for Neurological and Translational Sciences, QEll Medical Centre, RR Block, Ground Floor, 8 Verdun St, Nedlands, WA 6009, Australia. ${ }^{2}$ School of Health Sciences and Institute for Health Research, The University of Notre Dame Australia, Fremantle, WA 6160, Australia. ${ }^{3}$ Department of Neurosurgery, Sir Charles Gardiner Hospital, QEll Medical Centre, Western Nedlands 6009, Australia. ${ }^{4}$ Centre for Neuromuscular and Neurological Disorders, The University of Western Australia, Nedlands, WA 6009, Australia.

Received: 16 January 2018 Accepted: 1 February 2018 Published online: 09 February 2018

\section{References}

1. Kurinczuk JJ, White-Koning M, Badawi N. Epidemiology of neonatal encephalopathy and hypoxic-ischaemic encephalopathy. Early Hum Dev. 2010:86(6):329-38.

2. Graham EM, Ruis KA, Hartman AL, Northington FJ, Fox HE. A systematic review of the role of intrapartum hypoxia-ischemia in the causation of neonatal encephalopathy. Am J Obstet Gynecol. 2008;199(6):587-95.

3. Vannucci RC, Perlman JM. Interventions for perinatal hypoxic-ischemic encephalopathy. Pediatrics. 1997;100(6):1004-14.

4. Shankaran S. Therapeutic hypothermia for neonatal encephalopathy. Curr Treat Options Neurol. 2012:14(6):608-19.

5. Ferrer-Montiel AV, et al. Selected peptides targeted to the NMDA receptor channel protect neurons from excitotoxic death. Nat Biotechnol. 1998;16(3): 286-91

6. Marshall J, et al. Inhibition of N-methyl-d-aspartate-induced retinal neuronal death by Polyarginine peptides is linked to the attenuation of stressinduced Hyperpolarization of the inner mitochondrial membrane potential. J Biol Chem. 2015;290(36):22030-48.

7. Meloni BP, et al. Neuroprotective peptides fused to arginine-rich cell penetrating peptides: Neuroprotective mechanism likely mediated by peptide endocytic properties. Pharmacol Ther. 2015;153:36-54.

8. Meloni BP, et al. Poly-arginine and arginine-rich peptides are neuroprotective in stroke models. J Cereb Blood Flow Metab. 2015;35(6): 993-1004

9. Edwards AB, Anderton RS, Knuckey NW, Meloni BP. Characterisation of neuroprotective efficacy of modified poly-arginine-9 (R9) peptides using a neuronal glutamic acid excitotoxicity model. Mol Cell Biochem. 2017;426(12):75-85.

10. Meloni BP, Craig AJ, Milech N, Hopkins RM, Watt PM, Knuckey NW. The neuroprotective efficacy of cell-penetrating peptides TAT, penetratin, Arg-9, and Pep-1 in glutamic acid, kainic acid, and in vitro ischemia injury models using primary cortical neuronal cultures. Cell Mol Neurobiol. 2014;34(2):173-81.

11. Meloni BP, et a. Assessment of the Neuroprotective Effects of Arginine-Rich Protamine Peptides, Poly-Arginine Peptides (R12-Cyclic, R22) and ArginineTryptophan-Containing Peptides Following In Vitro Excitotoxicity and/or Permanent Middle Cerebral Artery Occlusion in Rats. NeuroMolecular Med. 2017;19(2-3):271-85.

12. McQueen J, et al. Pro-death NMDA receptor signaling is promoted by the GluN2B C-terminus independently of Dapk1. Elife. 2017;6:e17161.

13. Chiu LS, et al. Assessment of R18, COG1410, and APP96-110 in Excitotoxicity and traumatic brain injury. Transl Neurosci. 2017;8:147-57.

14. Milani D, Clark W, Cross JL, Anderton RS, Knuckey NW, Meloni BP. Polyarginine peptides reduce infarct volume in a permanent middle cerebral artery rat stroke model. BMC Neurosci. 2016;17(1):19.

15. Milani D, Cross لL, RS, Blacker DJ, Knuckey NW, Meloni BP. Neuroprotective efficacy of poly-arginin Andertone R18 and NA-1 (TAT-NR2B9C) peptides following transient middle cerebral artery occlusion in the rat. Neurosci Res. 2016;114:9-15.
16. Milani D, et al. The R18 Polyarginine peptide is more effective than the TAT-NR2B9C (NA-1) peptide when administered 60 minutes after permanent middle cerebral artery occlusion in the rat. Stroke Res Treat. 2016;2016:1-9.

17. Cook DR, et al. NMDA receptor modulation by the neuropeptide apelin: implications for excitotoxic injury. J Neurochem. 2011;118(6):1113-23.

18. García-Caballero A, et al. The deubiquitinating enzyme USP5 modulates neuropathic and inflammatory pain by enhancing Cav3.2 channel activity. Neuron. 2014;83(5):1144-58.

19. Xie JY, et al. Sustained relief of ongoing experimental neuropathic pain by a CRMP2 peptide aptamer with low abuse potential. Pain. 2016;157(9):2124-40.

20. MacDougall G, Anderton RS, Edwards AB, Knuckey NW, Meloni BP. The Neuroprotective Peptide Poly-Arginine-12 (R12) Reduces Cell Surface Levels of NMDA NR2B Receptor Subunit in Cortical Neurons; Investigation into the Involvement of Endocytic Mechanisms. J Mol Neurosci. 2017;61(2):235-46.

21. Brustovetsky T, Pellman JJ, Yang X-FF, Khanna R, Brustovetsky N. Collapsin response mediator protein 2 (CRMP2) interacts with $\mathrm{N}$-methyl-D-aspartate (NMDA) receptor and $\mathrm{Na}+/ \mathrm{Ca} 2+$ exchanger and regulates their functional activity. J Biol Chem. 2014;289(11):7470-82.

22. Sinai L, Duffy S, Roder JC. Src inhibition reduces NR2B surface expression and synaptic plasticity in the amygdala. Learn Mem. 2010;17(8):364-71.

23. Tu W, et al. DAPK1 interaction with NMDA receptor NR2B subunits mediates brain damage in stroke. Cell. 2010;140(2):222-34.

24. Brittain JM, et al. Neuroprotection against traumatic brain injury by a peptide derived from the collapsin response mediator protein 2 (CRMP2). J Biol Chem. 2011;286(43):37778-92.

25. Feldman P, Khanna R. Challenging the catechism of therapeutics for chronic neuropathic pain: targeting CaV2.2 interactions with CRMP2 peptides. Neurosci Lett. 2013:557 Pt A:27-36.

26. Birk AV, Chao WM, Liu S, Soong Y, Szeto HH. Disruption of cytochrome c heme coordination is responsible for mitochondrial injury during ischemia. Biochim Biophys Acta. 2015;1847(10):1075-84

27. Ferré $C A$, et al. Manipulation of the $\mathrm{N}$-terminal sequence of the Borna disease virus $X$ protein improves its mitochondrial targeting and neuroprotective potential. FASEB J. 2016:30(4):1523-33.

28. Rigobello MP, Barzon E, Marin O, Bindoli A. Effect of polycation peptides on mitochondrial permeability transition. Biochem Biophys Res Commun. 1995; 217(1):144-9.

29. Szelechowski M, et al. A viral peptide that targets mitochondria protects against neuronal degeneration in models of Parkinson's disease. Nat Commun. 2014:5:5181.

30. Szeto $\mathrm{HH}_{\text {, et }}$ al. Mitochondria-targeted peptide accelerates ATP recovery and reduces ischemic kidney injury. J Am Soc Nephrol. 2011;22(6):1041-52.

31. Zhao K, et al. Cell-permeable peptide antioxidants targeted to inner mitochondrial membrane inhibit mitochondrial swelling, oxidative cell death, and reperfusion injury. J Biol Chem. 2004:279(33):34682-90.

32. Cerrato CP, Pirisinu M, Vlachos EN, Langel Ü. Novel cell-penetrating peptide targeting mitochondria. FASEB J. 2015:29(11):4589-99.

33. Anbanandam A, Albarado DC, Tirziu DC, Simons M, Veeraraghavan S. Molecular basis for proline- and arginine-rich peptide inhibition of proteasome. J Mol Biol. 2008;384(1):219-27.

34. Gaczynska M, Osmulski PA, Gao Y, Post MJ, Simons M. Proline- and argininerich peptides constitute a novel class of allosteric inhibitors of proteasome activity. Biochemistry. 2003:42(29):8663-70.

35. Cameron A, Appel J, Houghten RA, Lindberg I. Polyarginines are potent Furin inhibitors. J Biol Chem. 2000;275(47):36741-9.

36. Fugere M, Appel J, Houghten RA, Lindberg I, Day R. Short polybasic peptide sequences are potent inhibitors of PC5/6 and PC7: use of positional scanning-synthetic peptide combinatorial libraries as a tool for the optimization of inhibitory sequences. Mol Pharmacol. 2007;71(1):323-32

37. Kacprzak MM, et al. Inhibition of furin by polyarginine-containing peptides: nanomolar inhibition by nona-D-arginine. J Biol Chem. 2004; 279(35):36788-94

38. Tian S, Huang Q, Fang Y, Wu J. FurinDB: a database of 20-residue furin cleavage site motifs, substrates and their associated drugs. Int J Mol Sci. 2011;12(2):1060-5

39. Doeppner TR, et al. Systemic Proteasome inhibition induces sustained poststroke neurological recovery and Neuroprotection via mechanisms involving reversal of peripheral Immunosuppression and preservation of blood-brainbarrier integrity. Mol Neurobiol. 2016;53(9):6332-41.

40. Wojcik C, Di Napoli M. Ubiquitin-proteasome system and proteasome inhibition: new strategies in stroke therapy. Stroke. 2004;35(6):1506-18. 
41. Yang Y, Zhang X, Cui H, Zhang C, Zhu C, Li L. Apelin-13 protects the brain against ischemia/reperfusion injury through activating PI3K/Akt and ERK1/2 signaling pathways. Neurosci Lett. 2014;568:44-9.

42. Hilchie AL, Wuerth K, Hancock REW. Immune modulation by multifaceted cationic host defense (antimicrobial) peptides. Nat Chem Biol. 2013;9(12):761-8.

43. Kellett DN. On the anti-inflammatory activity of Protamine Sulphate and of Hexadimethrine bromide, inhibitors of plasma Kinin formation. $\mathrm{Br} J$ Pharmacol Chemother. 1965;24:705-13.

44. Li L-H, et al. A synthetic cationic antimicrobial peptide inhibits inflammatory response and the NLRP3 inflammasome by neutralizing LPS and ATP. PLOS One. 2017;12(7):e0182057.

45. Courderot-Masuyer C, Dalloz F, Maupoil V, Rochette L. Antioxidant properties of aminoguanidine. Fundam Clin Pharmacol. 1999;13(5):535-40.

46. Yildiz G, Demiryürek AT, Sahin-Erdemli I, Kanzik I. Comparison of antioxidant activities of aminoguanidine, methylguanidine and guanidine by luminolenhanced chemiluminescence. Br J Pharmacol. 1998;124(5):905-10.

47. Lass A, Suessenbacher A, Wölkart G, Mayer B, Brunner F. Functional and analytical evidence for scavenging of oxygen radicals by $\mathrm{L}$-arginine. Mol Pharmacol. 2002;61(5):1081-8.

48. Mandal SM, et al. Identification of multifunctional peptides from human milk. Peptides. 2014;56:84-93.

49. Marshall J, et al. Inhibition of N-methyl-D-aspartate-induced retinal neuronal death by Polyarginine peptides is linked to the attenuation of stressinduced Hyperpolarization of the inner mitochondrial membrane potential. J Biol Chem. 2015;290(36):22030-48.

50. Nijboer CH, van der Kooij MA, van Bel F, Ohl F, Heijnen CJ, Kavelaars A. Inhibition of the JNK/AP-1 pathway reduces neuronal death and improves behavioral outcome after neonatal hypoxic-ischemic brain injury. Brain Behav Immun. 2010;24(5):812-21.

51. Tan $X$, et al. The inhibition of Cdk5 activity after hypoxia/ischemia injury reduces infarct size and promotes functional recovery in neonatal rats. Neuroscience. 2015;290:552-60.

52. van der Kooij MA, et al. NF-kappaB inhibition after neonatal cerebral hypoxia-ischemia improves long-term motor and cognitive outcome in rats. Neurobiol Dis. 2010;38(2):266-72.

53. Zhou M, Xu W, Liao G, Bi X, Baudry M. Neuroprotection against neonatal hypoxia/ischemia-induced cerebral cell death by prevention of calpainmediated mGluR1alpha truncation. Exp Neurol. 2009;218(1):75-82.

54. Bolouri $\mathrm{H}$, et al. Innate defense regulator peptide 1018 protects against perinatal brain injury. Ann Neurol. 2014;75(3):395-410.

55. McAdoo JD, Warner DS, Goldberg RN, Vitek MP, Pearlstein R, Laskowitz DT. Intrathecal administration of a novel apoE-derived therapeutic peptide improves outcome following perinatal hypoxic-ischemic injury. Neurosci Lett. 2005;381(3):305-8.

56. Stalmans $\mathrm{S}$, et al. Cell-penetrating peptides selectively cross the blood-brain barrier in vivo. PLoS One. 2015;10(10):e0139652.

57. Sarko D, et al. The pharmacokinetics of cell-penetrating peptides. Mol Pharm. 2010;7(6):2224-31.

58. Zou L-L, Ma J-L, Wang T, Yang T-B, Liu C-B. Cell-penetrating peptidemediated therapeutic molecule delivery into the central nervous system. Curr Neuropharmacol. 2013;11(2):197-208.

59. Nijboer $\mathrm{CH}$, Heijnen CJ, Groenendaal F, van Bel F, Kavelaars A. Alternate pathways preserve tumor necrosis factor-alpha production after nuclear factor-kappaB inhibition in neonatal cerebral hypoxia-ischemia. Stroke. 2009; 40(10):3362-8

60. Edwards AB, et al. Modification to the Rice-Vannucci perinatal hypoxicischaemic encephalopathy model in the P7 rat improves the reliability of cerebral infarct development after 48 hours. J Neurosci Methods. 2017;288:62-71.

61. CJ Heyser. Assessment of Developmental Milestones in Rodents. In: Current Protocols in Neuroscience. Hoboken, NJ, USA: John Wiley \& Sons, Inc; 2004. vol. Chapter 8. p. Unit 8.18

62. de Vries LS, Groenendaal F. Patterns of neonatal hypoxic-ischaemic brain injury. Neuroradiology. 2010;52(6):555-66.

63. Roe SY, Rothwell NJ. Whole body metabolic responses to brain trauma in the rat. J Neurotrauma. 1997;14(6):399-408.

64. Wiegler K, Bonny C, Coquoz D, Hirt L. The JNK inhibitor XG-102 protects from ischemic damage with delayed intravenous administration also in the presence of recombinant tissue Plasminogen activator. Cerebrovasc Dis. 2008;26(4):360-6.

65. Vaslin A, Naegele-Tollardo S, Puyal J, Clarke PGH. Excitotoxicity-induced endocytosis mediates neuroprotection by TAT-peptide-linked JNK inhibitor. J Neurochem. 2011;119(6):1243-52.

\section{Submit your next manuscript to BioMed Central and we will help you at every step:}

- We accept pre-submission inquiries

- Our selector tool helps you to find the most relevant journal

- We provide round the clock customer support

- Convenient online submission

- Thorough peer review

- Inclusion in PubMed and all major indexing services

- Maximum visibility for your research

Submit your manuscript at www.biomedcentral.com/submit
C Biomed Central 